\title{
Apoptosis Marker
}

National Cancer Institute

\section{Source}

National Cancer Institute. Apoptosis Marker. NCI Thesaurus. Code C114790.

A molecule or collection of biological compounds that can be objectively measured to evaluate the extent of programmed cell death occurring in a biological sample. 